megaloblastic anaemia after taking metformin for eight years. True pernicious anaemia was excluded. There was no evidence of a lesion in the distal ileum and generalised malabsorption was excluded. We presumed that the vitamin $B_{12}$ malabsorption was related to the effect of metformin on active absorption in the distal ileum but we could not prove that. The anaemia was cured, and treatment with chlorpropamide, metformin, and cyanocobalamin was continued.

Although vitamin $B_{12}$ malabsorption is relatively common with long-term metformin treatment, we think this is the first reported case of megaloblastic anaemia. The rarity of this complication might be expected since the malabsorption is not complete and the normal body stores contain more than a year's supply of vitamin $B_{12}$. We advise annual screening for megaloblastic anaemia in patients on long-term metformin treatment, as it is an easily remediable complication and does not necessitate withdrawal of the drug.

1 Tomkin G, Hadden D, Weaver J, Montgomery D. Vitamin $B_{12}$ status of patients on long-term metformin therapy. $\mathrm{Br} M e d \mathcal{F} 1971$;ii:685-7.

2 Tomkin G. Malabsorption of vitamin $B_{12}$ in diabetic patients treated with

phenformin: a comparison with metformin. Br Med f 1973;iii:673-5.

3 Nattrass M, Alberti KGMM. Biguanides. Diabetologia 1978;14:71-4.

(Accepted 12 February 1980)

Metabolic Unit, Royal Victoria Hospital, Belfast, BT12 6BA

T S CALLAGHAN, MRCP, registrar

D R HADDEN, MD, FRCPED, consultant physician

Metabolic Unit, The Adelaide Hospital, Dublin 8

G H TOMKIN, MD, FRCPI, consultant physician

\section{Two new modes of desmopressin (DDAVP) administration}

The standard form of replacement treatment for diabetes insipidus in recent years has been the vasopressin analogue desmopressin (DDAVP). This produces a prolonged antidiuresis, lasting up to 20 hours, after intranasal or parenteral administration without the side effects associated with pitressin, such as vascular constriction or smooth muscle spasm. ${ }^{1}$ A major problem, however, is the difficulty in administering desmopressin intranasally in the commonly used rhinyle. The technique is rapidly learnt by some patients and gradually by most, but some never manage it. The control of diabetes insipidus, therefore, may be variable. We describe two new modes of administering desmopressin and compare them with rhinyle administration.

\section{Methods and results}

(1) A metered-dose nasal spray was used that delivered desmopressin as a fine spray. The spray was inserted into the entrance to one nostril and the patient was required to sniff as the spray was activated. (2) Desmopressin was included in a gelatin-based lozenge, which was placed under the tongue and allowed to dissolve. Two puffs of the spray or one lozenge were taken to be equivalent to $10 \mu \mathrm{g}$ of desmopressin given by the rhinyle. We administered the spray and lozenges to two groups of six patients with confirmed cranial diabetes insipidus and compared their use with administration of desmopressin by rhinyle. All six patients were tested with two lozenges, and two of them also had a single sublingual lozenge on a separate occasion. In all, there were eight patients with cranial diabetes insipidus established on the basis of water deprivation tests-three males and five females, with an age range of 11-64 years.

The method used for assessing antidiuresis was that described by Edwards et al. ${ }^{1}$ At 830 am the patient was given a one-litre oral water load $(500 \mathrm{ml}$ in the case of the 11-year-old patient), and the urine flow rate was subsequently stabilised by giving oral fluids in a volume equivalent to that of the urine passed. When the flow rate was stable desmopressin was given by either the rhinyle or one of the new modes of administration. All the patients normally took $20 \mu \mathrm{g}$ desmopressin daily but had been off treatment for 24 hours. The volume of urine passed at each time interval was noted and its osmolality measured. The results were analysed by the non-parametric Walsh test. ${ }^{2}$ There was no significant difference between rhinyle and spray or rhinyle and lozenges in terms of urine flow or osmolality at any time up to 20 hours (figure). The responses of two patients to one and to two lozenges were also compared. The speed of onset and maximal effect of the single lozenge were similar to those of two lozenges, but the effect wore off more quickly. Every patient preferred the spray to the rhinyle, while there was a marginal preference for the rhinyle rather than the lozenges.

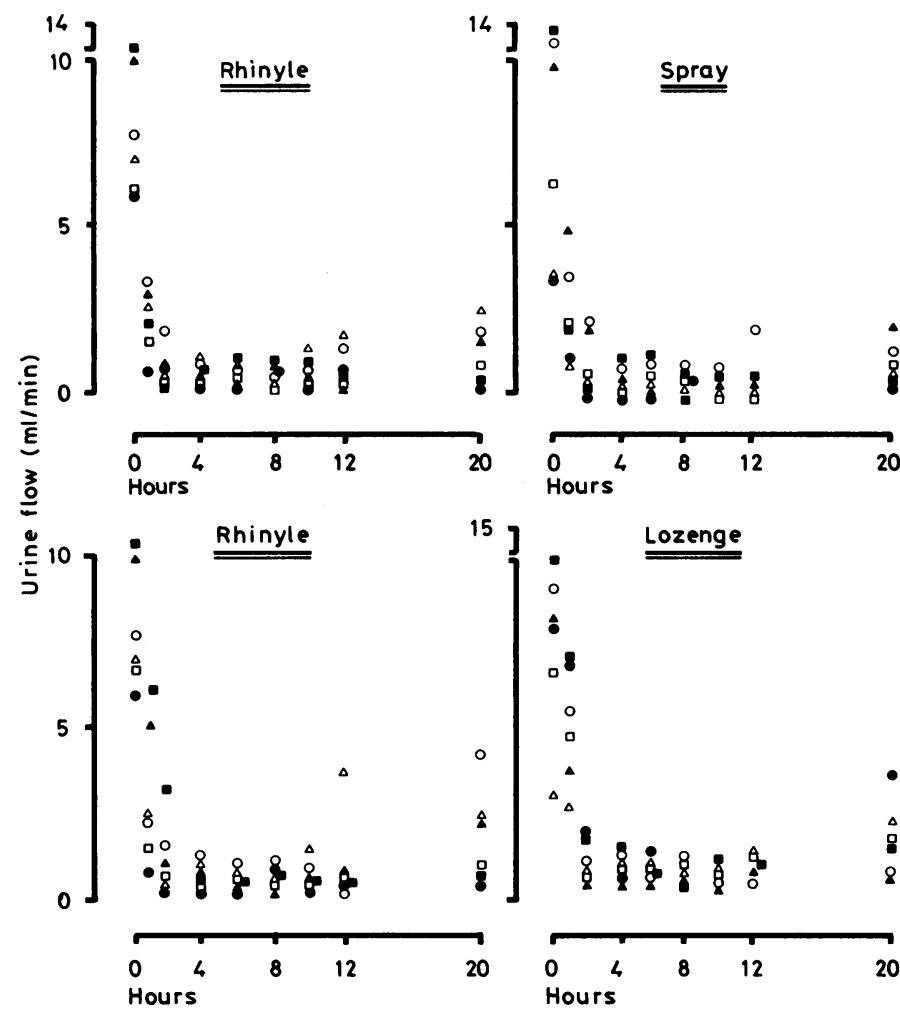

Changes in urine osmolality after DDAVP. Comparisons between rhinyle and spray (above) and between rhinyle and two lozenges (below). Symbols refer to responses in same subjects.

\section{Comment}

Desmopressin given by nasal spray or sublingual lozenge was at least as potent as by rhinyle, in the doses used, in terms of maximal antidiuresis and duration of action. Each produced a potent antidiuresis of rapid onset lasting 10-12 hours followed by a gradual loss of control over the next 12 hours. The nasal spray is simple and efficient, was generally preferred by our patients, and was better than the rhinyle for giving desmopressin, particularly when starting new patients on treatment. This is particularly important in the very young, the very old, and the partially sighted-groups that tend to have special problems using the rhinyle. On the other hand, the advantages of the sublingual lozenges seem fewer. Although obviously effective, at present they should probably be used only when intranasal administration is impossible, as during severe attacks of rhinitis or coryza.

The DDAVP nasal spray and sublingual lozenges were provided by Dr B Donovan, Ferring Pharmaceuticals, Malmö, Sweden. The rhinyle spray and lozenges are not yet commercially available in the United Kingdom.

1 Edwards CRW, Kitau MJ, Chard T, Besser GM. Vasopressin analogue DDAVP in diabetes insipidus: clinical and laboratory studies. $\mathrm{Br} \mathrm{Med} \mathcal{F}$ 1973 ;iii :375-8.

2 Siegel S. Non-parametric statistics. New York: McGraw Hill, 1956.

(Accepted 5 February 1980)

Department of Endocrinology, St Bartholomew's Hospital, London EC1A 7BE

ASHLEY GROSSMAN, BA, MRCP, MRC training fellow

A FABBRI, medical student

P L GOLDBERG, BA, medical student

G M BESSER, MD, FRCP, professor of endocrinology

\section{Correction}

Gall-bladder sensitivity to cholecystokinin in patients with gall stones

An error occurred in this paper by Dr T C Northfield and others (19 January, p 143). Cholecystokinin values are expressed throughout in $\mathrm{mU}$ (Ivy dog)/ $\mathrm{kg} / \mathrm{min}$. They should have been expressed in Ivy dog units/ $\mathrm{kg} / \mathrm{min}$. 